\title{
The impact of adjustment latitude on self- assessed work ability in regard to gender and occupational type
}

Gun Johansson, Hanna Hultin, Jette Möller, Johan Hallqvist and Katarina Kjellberg

\section{Linköping University Post Print}

N.B.: When citing this work, cite the original article.

Original Publication:

Gun Johansson, Hanna Hultin, Jette Möller, Johan Hallqvist and Katarina Kjellberg, The impact of adjustment latitude on self-assessed work ability in regard to gender and occupational type, 2012, Scandinavian Journal of Occupational Therapy, (19), 4, 350-359. http://dx.doi.org/10.3109/11038128.2011.603354

Copyright: Informa Healthcare http://informahealthcare.com/

Postprint available at: Linköping University Electronic Press

http://urn.kb.se/resolve?urn=urn:nbn:se:liu:diva-71440 
Abstract

Introduction:

Sickness absence reflects reduced work ability, which is determined by health and demands at work. Adjustment latitude describes opportunities to change demands at work to improve health. The aim is to study the association between adjustment latitude and self-assessed work ability among men and women and employees from different occupational sector.

Methods:

This cross-sectional study used data from a questionnaire sent to 3020 employees in three occupational sectors in Sweden; 1,430 responded. Subjects were divided into three groups: full, moderately reduced and greatly reduced work ability depending on their own assessment. Presence of nine adjustment opportunities at work was requested and subjects were divided into three groups: few, intermediate and many opportunities. The association between work ability and each of the nine specific opportunities was also analyzed. Multinomial logistic regression was used for analyses.

Results:

The number of opportunities to adjust was associated with self-assessed work ability among men and employees in health care. "Shortening the working day" was associated with work ability in several of the groups studied. For men and industrial employees, "postponing work", "going home and working later" and "working without disturbance" were associated with work ability. "Being able to work from home" was associated with work ability among women and employees in insurance.

Conclusions:

The assumption that adjustment latitude at work affects work ability is supported. Associations differ in regard to gender and occupational sectors. As this is the first study of the relation between adjustment latitude and work ability, studies with longitudinal design and alternative samples are needed.

Key words: work ability, work conditions, gender, occupation, cross-sectional

\section{Introduction}


There is growing evidence that long sickness absence for the individual has adverse consequences on, for example, finance, health and the development of salaries and careers [1-3]. Whether poor health causes absence from work largely depends on how it affects work ability. However, reduced work ability is not only determined by poor health. By interacting with non-medical conditions, one and the same health problem may to different degrees result in reduced ability to work [4]. In order to provide effective vocational services for disabled we need to identify these non-medical conditions affecting work ability.

Poor health may be such that in all or in most cases it results in absence from work as no or very little work ability remains. Several studies have shown associations between poor health and work ability, although the strength of the associations may differ with the diagnosis [5-7]. However, often the relation between poor health and work ability depends on demands at work. These demands can to varying degrees be modified to meet the health problem. Johansson \& Lundberg [8]] introduced the concept of adjustment latitude at work to describe employees' various opportunities to change their jobs to achieve work ability when they have symptoms of poor health. Adjustment latitude describes opportunities to alter work to health and encompasses e.g. to choose among work tasks, to change the place and time of work and to work at a slower pace.

It is assumed that such opportunities will affect whether employees can remain in work or not when ill by affecting work ability (Fig 1). Nordenfelt [9] recently published a definition of the concept of work ability in which opportunities to adjust work are a crucial component.

Johansson et al $[8,10]$ found based on cross-sectional data that low adjustment latitude increased the likelihood for sickness absence both for 1 to 7 days and above 8 days, and decreased the likelihood for long-term sick to return to work. Hultin et al [11] showed in a prospective cohort study that the likelihood to report sick was higher among employees with low adjustment latitude 
compared to employees with high adjustment latitude. Hultin et al also found that the association between adjustment latitude and sickness absence differed among different occupational sectors

The assumption that the association between adjustment latitude and sickness absence is mediated through work ability has not yet been tested. The aim here is to study whether adjustment latitude is associated with self-assessed work ability among men and women and employees in various

occupational sectors.

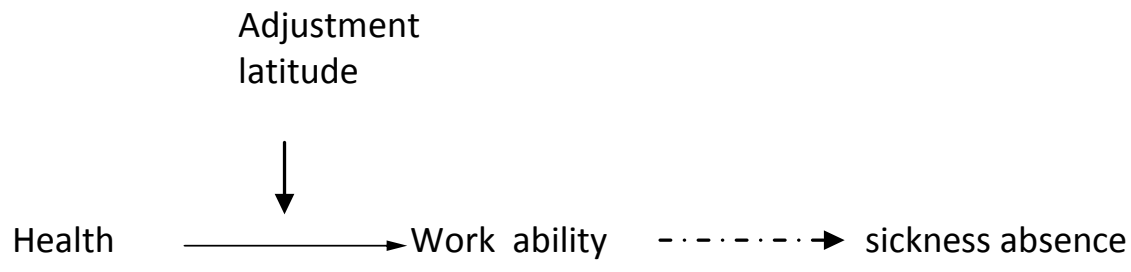

Fig 1. A hypothesis regarding the relation between adjustment latitude, health, work ability and sickness absence

\section{Methods}

\section{Material}

Data was collected from the TUFS study, which in Swedish is an acronym for "Triggers of sickness absence". In the present study, data from the baseline questionnaires in the TUFS study were 
analyzed in a cross-sectional design. Employees from six workplaces within three occupational sectors in Sweden, four public and municipal health care facilities, one manufacturing plant and one insurance company, were recruited for the study. These workplaces were strategically recruited through contacts with organisation management. All employees who were in active employment (i.e. not on parental leave, sick leave more than 30 days or other leave of absence) and had a contract for more than three months' future employment, in total 3,020 employees, were invited to participate by filling in a postal questionnaire and signing a consent form. In cases of non-response, three consecutive reminders were sent out. 1,430 subjects ( $56 \%$ women and $44 \%$ men) agreed to participate, giving a response rate of $47 \%$. Participants were $19-68$ (mean 45 ) years old; $28 \%$ were employed in health care facilities, $36 \%$ in the manufacturing industry and $36 \%$ in the insurance company. The response rate varied between work places. The highest percentage responding (61 \%) were among employees in the industrial work place and the lowest (32\%) where among employees in one of the work places performing health care. Annual sick leave incidence was generally lower among participants than non-participants. Information on gender and age for the non-participants was available in three of the six work places. In all three work places the proportion women is higher among participants than among non-participants and the median age is also higher among participants than among non-participants (table 1). The data collection was carried out between 2005 and 2006. The study was approved by the regional ethics committee in

\section{Stockholm.}

Table 1 Number of responders and proportion responding at the six work places

\begin{tabular}{clcc} 
work place & Branch & $\mathrm{n}$ & Response rate \% \\
\hline 1 & Industry & 508 & 61 \\
2 & Insurance & 516 & 48 \\
3 & Health Care & 92 & 32 \\
4 & Health Care & 263 & 37 \\
5 & Health Care & 37 & 41 \\
6 & Health Care & 14 & 54
\end{tabular}




\section{Independent variables}

Information on adjustment latitude was obtained by a question concerning different specific types of opportunities to adjust work. The types of opportunities were developed from answers to an open ended question in a questionnaire where 200 employees were asked to describe the opportunities to adjust work which were present in their job [4]. The question read "In what ways are you able to adjust your work on days when you feel out of sorts, have pain, have a cold or something similar?" Nine different types of opportunities to adjust work were presented: a) can do the necessary work and postpone the rest; b) can choose among tasks; c) can get help from workmates; d) can work at a slower pace; e) can take longer breaks; f) can shorten the working day; g) can go home and do work later; h) can work without being disturbed at the workplace; i) can work from home. For each item, the subjects were asked to answer "yes" or "no". The "yes" responses were summed up in an adjustment latitude index ranging from zero to nine. This index was categorized in three groups: few (0-3), intermediate (4-6) and many (7-9) opportunities. This index has previously been used in studies of the relation between adjustment latitude and sickness absence[8, 11, 12].

188 subjects did not answer all nine questions on adjustment latitude. Of these, 51 omitted only a few items and could be placed in their adjustment category irrespective of answers to the omitted items. This provided information on adjustment latitude from $90 \%$ of the subjects. In addition, each type of opportunity was dealt with as a separate variable.

\section{Outcome variable}

Self-assessed work ability was used as the outcome. The subjects were asked to score their general work ability on a scale from 0 , corresponding to the subject not being able to work at all, to 10 , corresponding to the subject's best possible work ability. The work ability score was categorized in 
three classes: "greatly reduced work ability" (score 0-7), "moderately reduced work ability" (score 8-9) and "full work ability" (score 10). As the majority of subjects (65\%) had assessed their work ability as " 10 " and only $9 \%$ had assessed it as "7" or below, this categorization gave a reasonable representation in the three groups.

\section{Confounders}

All analyses were adjusted for age and self-reported health (SRH). Information on SRH was obtained through the question: "How do you rate your health in general?" with five alternative answers: "very good", "good", "fair", "bad" and "very bad". The answers were dichotomized into "good health" (very good-good) and "poor health" (fair-very bad). The rationale for dichotomizing SRH was the low number of responses in the bad" and "very bad" categories.

\section{Analysis}

Analyses were performed using a multinomial logistic regression model which handles categorical data at more than two levels. The present outcome variable had three values: greatly reduced work ability, moderately reduced work ability and full work ability. The odds ratios for reporting moderately and greatly reduced work ability compared to full work ability were computed in relation to the number of opportunities to adjust and specific opportunities to adjust. For all ORs, $95 \%$ confidence intervals were computed.

Stratified analyses were performed for gender and occupational sector. The analyses stratified for gender were adjusted for age, SRH and occupational type, while the analyses stratified for occupational sector were adjusted for age, SRH and gender. All analyses were made using SPSS Statistics 17.0. 


\section{Results}

The majority of men (63\%) and women (67\%) assessed their work ability as full and nine percent of both men and women assessed their general work ability as greatly reduced

(Table II). Seventy-four percent of the employees in the insurance company regarded their work ability as full compared to $61 \%$ of employees in the health care sector and $58 \%$ employed in industry.

Table II: Distribution of work ability in regard to gender and occupational type

\begin{tabular}{llccc} 
& & $\begin{array}{c}\text { Greatly } \\
\text { reduced } \\
\text { work ability }\end{array}$ & $\begin{array}{c}\text { Moderately } \\
\text { reduced } \\
\text { work ability }\end{array}$ & $\begin{array}{c}\text { Full work } \\
\text { ability }\end{array}$ \\
\cline { 3 - 5 } Gender & Men & $9(5)$ & $\%(n)$ & $\%(n)$ \\
\cline { 3 - 5 } & Women & $9(71)$ & $28(174)$ & $63(387)$ \\
Occupational- & Industry & $10(48)$ & $32(161)$ & $67(521)$ \\
type & Insurance & $6(28)$ & $20(102)$ & $74(378)$ \\
& Health care & $14(54)$ & $26(102)$ & $61(240)$
\end{tabular}

The distribution on reported work ability was similar among men and women. Thirteen percent of the women and $14 \%$ of the men with few opportunities to adjust reported greatly reduced work ability. Comparable figures for those with many opportunities to adjust were $7 \%(w)$ and $6 \%(m)$ (Table III a). Thirteen percent of industrial employees with few opportunities to adjust reported greatly reduced ability, while the comparable figure for those with many opportunities was $6 \%$ (Table III b). Among employees in the insurance company, there was a small difference in the proportion reporting greatly reduced work ability in regard to the number of opportunities to adjust. The difference in regard to opportunities to adjust was in reporting moderately reduced ability. Among employees in health care, reporting greatly and moderately reduced work ability had a U-shaped association, although in different directions, to adjustment latitude. 
Seventy-three percent of women and $72 \%$ of men who can shorten their working day reported full work ability, while among those lacking this opportunity only $58 \%$ of women and $55 \%$ of men reported such ability (Table III a). Among industrial employees, the proportion reporting full work ability was 20 percentage points higher among those who are able to shorten their working day when feeling ill than among those that cannot (Table III b). Access or not to this opportunity gave different percentages reporting full and reduced ability among employees in insurance and health care as well, although the differences were smaller.

Men and women who are able to postpone and/or choose among work tasks have bigger percentages reporting full work ability ( $w=70 \%$ for both; $m=68 \%$ for both) compared to those that cannot ( $w=59 \%$ and $60 \% ; m=56 \%$ on both) (Table III a). Whether one can change work tasks in these respects also gives different distributions of reported work ability among employees in all the occupational sectors studied, although the differences among employees in insurance were smaller than in the other sectors (Table III b). Among men and industrial employees, those that are able to go home and do work later and work without disturbance when feeling ill have between 14 and 20 percent points higher reporting full work ability compared to those that are not (Table II b). Seventy-five percent among men who are able to work from home report full work ability compared to $59 \%$ among those that cannot.

Whether one can get help from work mates, work at a slower pace and/or take longer breaks had a rather weak association with the assessments of work ability. 
Table III a

Proportions (\%) and number(n) of women and men assessing their work ability as greatly reduced, moderately reduced or full in regard to adjustment latitude

\begin{tabular}{lr}
\multicolumn{2}{l}{ Adjustment latitude } \\
\hline Number & few \\
of adjust- & inter- \\
ments & mediate \\
& many
\end{tabular}

\begin{tabular}{cccccc}
\hline & Women & \multicolumn{5}{c}{ Men } \\
\hline $\begin{array}{c}\text { Greatly } \\
\text { reduced work } \\
\text { ability }\end{array}$ & $\begin{array}{l}\text { Moderately } \\
\text { reduced work } \\
\text { ability }\end{array}$ & $\begin{array}{c}\text { Full work } \\
\text { ability }\end{array}$ & $\begin{array}{c}\text { Greatly } \\
\text { reduced work } \\
\text { ability }\end{array}$ & $\begin{array}{c}\text { Moder- } \\
\text { ately reduced } \\
\text { work ability }\end{array}$ & $\begin{array}{c}\text { Full work } \\
\text { ability }\end{array}$ \\
\hline$\%(\mathrm{n})$ & $\%(\mathrm{n})$ & $\%(\mathrm{n})$ & $\%(\mathrm{n})$ & $\%(\mathrm{n})$ & $\%(\mathrm{n})$ \\
\hline & & & & & \\
$13(41)$ & $26(82)$ & $61(191)$ & $14(33)$ & $31(73)$ & $55(128)$ \\
$7(16)$ & $29(68)$ & $65(154)$ & $5(9)$ & $30(50)$ & $65(109)$ \\
$7(12)$ & $18(30)$ & $75(123)$ & $6(9)$ & $21(32)$ & $74(115)$
\end{tabular}

\section{Specific adjustments}

\begin{tabular}{|c|c|c|c|c|c|c|c|}
\hline $\begin{array}{l}\text { Postpone } \\
\text { work }\end{array}$ & $\begin{array}{r}\text { no } \\
\text { yes }\end{array}$ & $\begin{array}{c}13(40) \\
7(29)\end{array}$ & $\begin{array}{l}28(89) \\
23(96)\end{array}$ & $\begin{array}{l}59(188) \\
70(289)\end{array}$ & $\begin{array}{c}15(36) \\
5(17)\end{array}$ & $\begin{array}{l}29(68) \\
27(90)\end{array}$ & $\begin{array}{l}56(133) \\
68(227)\end{array}$ \\
\hline \multirow{4}{*}{$\begin{array}{l}\text { Choose } \\
\text { among work } \\
\text { tasks } \\
\text { Get help } \\
\text { from work } \\
\text { mates }\end{array}$} & no & $13(42)$ & $27(87)$ & 60(193) & 14(32) & 30(70) & $56(128))$ \\
\hline & yes & $7(27)$ & 24(97) & $70(286)$ & $6(21)$ & 26(87) & $68(231)$ \\
\hline & no & $12(36)$ & $19(58)$ & $69(212)$ & $12(21)$ & $24(41)$ & 64(110) \\
\hline & yes & $8(33)$ & $29(124)$ & $63(267)$ & $8(32)$ & $29(116)$ & $63(248)$ \\
\hline \multirow{2}{*}{$\begin{array}{l}\text { Work at a } \\
\text { slower pace }\end{array}$} & no & $11(32)$ & 28(79) & 61(176) & $12(27)$ & $28(63)$ & $60(132)$ \\
\hline & yes & $9(38)$ & 24(105) & $68(300)$ & $7(25)$ & 27(91) & $66(226)$ \\
\hline \multirow{2}{*}{$\begin{array}{l}\text { Take longer } \\
\text { breaks }\end{array}$} & no & $10(48)$ & $27(124)$ & $63(289)$ & $11(34)$ & 29(90) & 60(189) \\
\hline & yes & $8(20)$ & $22(57)$ & 70(181) & $7(18)$ & $26(66)$ & $67(167)$ \\
\hline \multirow{2}{*}{$\begin{array}{l}\text { Shorten the } \\
\text { working } \\
\text { day }\end{array}$} & no & $14(51)$ & 28(98) & 58(205) & $12(35)$ & 33(95) & $55(158)$ \\
\hline & yes & $5(19)$ & $23(84)$ & $73(271)$ & 6(15) & $23(63)$ & $72(197)$ \\
\hline \multirow{2}{*}{$\begin{array}{l}\text { Go home } \\
\text { and do work } \\
\text { later }\end{array}$} & no & 11(50) & $26(118)$ & 63(285) & $11(41)$ & $33(122)$ & $56(209)$ \\
\hline & yes & $7(20)$ & $25(67)$ & $68(186)$ & $6(11)$ & 19(36) & $76(148)$ \\
\hline \multirow{2}{*}{$\begin{array}{l}\text { Work } \\
\text { without } \\
\text { disturb- } \\
\text { ance }\end{array}$} & no & $8(40)$ & 27(137) & 65(329) & $12(40)$ & 32(109) & $57(194)$ \\
\hline & yes & $14(30)$ & $21(45)$ & $66(145)$ & $6(12)$ & $22(47)$ & $73(157)$ \\
\hline \multirow{2}{*}{$\begin{array}{l}\text { Work from } \\
\text { home }\end{array}$} & no & 9(55) & 27(159) & $64(375)$ & $10(45)$ & $30(134)$ & $59(262)$ \\
\hline & yes & 10(15) & $17(25)$ & 72(105) & $6(7)$ & 19(23) & 75(92) \\
\hline
\end{tabular}


Table III b

Proportions (\%) and number(n) of employees in industry, insurance and health care assessing their work ability as greatly reduced, moderately reduced or full in regard to adjustment latitude

\begin{tabular}{|c|c|c|c|c|c|c|c|c|}
\hline \multicolumn{3}{|c|}{ Industry } & \multicolumn{3}{|c|}{ Insurance } & \multicolumn{3}{|c|}{ Health-Care } \\
\hline $\begin{array}{c}\text { Greatly } \\
\text { reduced } \\
\text { work } \\
\text { ability }\end{array}$ & $\begin{array}{l}\text { Moder- } \\
\text { ately } \\
\text { reduced } \\
\text { work } \\
\text { ability }\end{array}$ & $\begin{array}{c}\text { Full work } \\
\text { ability }\end{array}$ & $\begin{array}{c}\text { Greatly } \\
\text { reduced } \\
\text { work } \\
\text { ability }\end{array}$ & $\begin{array}{c}\text { Moder- } \\
\text { ately } \\
\text { reduced } \\
\text { work } \\
\text { ability }\end{array}$ & $\begin{array}{c}\text { Full work } \\
\text { ability }\end{array}$ & $\begin{array}{c}\text { Greatly } \\
\text { reduced } \\
\text { work ability }\end{array}$ & $\begin{array}{c}\text { Moderately } \\
\text { reduced work } \\
\text { ability }\end{array}$ & $\begin{array}{c}\text { Full work } \\
\text { ability }\end{array}$ \\
\hline$\%(n)$ & $\%(n)$ & $\%(n)$ & $\%(n)$ & $\%(n)$ & $\%(n)$ & $\%(n)$ & $\%(n)$ & $\%(n)$ \\
\hline
\end{tabular}

\begin{tabular}{|c|c|c|c|c|c|c|c|c|c|c|}
\hline \multicolumn{11}{|c|}{ Adjustment latitude } \\
\hline \multirow{4}{*}{$\begin{array}{l}\text { Number of } \\
\text { adjust- } \\
\text { ments }\end{array}$} & few & $13(31)$ & $33(79)$ & $54(127)$ & $7(8)$ & $25(27)$ & $68(74)$ & $18(36)$ & $24(49)$ & $58(118)$ \\
\hline & inter- & $5(7)$ & $34(46)$ & $61(84)$ & $5(9)$ & 23(39) & $72(124)$ & $9(9)$ & $34(33)$ & $57(56)$ \\
\hline & $\begin{array}{l}\text { med. } \\
\text { many }\end{array}$ & $6(4)$ & 26(19) & $69(50)$ & $5(10)$ & $17(32)$ & 78(152) & $12(7)$ & 19(11) & $68(39)$ \\
\hline & \multicolumn{10}{|c|}{ Specific adjustments } \\
\hline \multirow{2}{*}{$\begin{array}{l}\text { Post-pone } \\
\text { work }\end{array}$} & no & $14(33)$ & $32(78)$ & $55(134)$ & $6(6)$ & $26(26)$ & $69(70)$ & $18(38)$ & $26(53)$ & $56(117)$ \\
\hline & yes & $5(11)$ & $32(70)$ & $63(139)$ & $6(21)$ & $20(74)$ & $75(281)$ & $9(14)$ & $27(42)$ & $64(100)$ \\
\hline \multirow{3}{*}{$\begin{array}{c}\text { Choose } \\
\text { among } \\
\text { work tasks } \\
\text { Get help }\end{array}$} & no & $12(29)$ & $32(74)$ & $56(130)$ & $8(9)$ & $23(27)$ & $69(80)$ & $18(37)$ & $27(56)$ & $55(112)$ \\
\hline & yes & $7(15)$ & $32(72)$ & $62(140)$ & $5(18)$ & $20(74)$ & $75(276)$ & 10(15) & $24(38)$ & $66(104)$ \\
\hline & & & & & & & & & & \\
\hline \multirow{2}{*}{$\begin{array}{l}\text { from work } \\
\text { mates }\end{array}$} & no & $12(13)$ & $27(30)$ & $62(69)$ & $8(17)$ & $18(36)$ & $74(152)$ & $17(27)$ & $20(33)$ & $63(103)$ \\
\hline & yes & $9(31)$ & $34(117)$ & $57(198)$ & $4(10)$ & $23(62)$ & $74(204)$ & $12(25)$ & $30(61)$ & $57(115)$ \\
\hline \multirow{2}{*}{$\begin{array}{l}\text { Work at a } \\
\text { slower pace }\end{array}$} & no & $11(24)$ & $30(64)$ & $59(125)$ & $6(6)$ & $25(26)$ & $69(72)$ & $15(29)$ & $27(52)$ & $58(112)$ \\
\hline & yes & $8(19)$ & $33(79)$ & $59(140)$ & $6(21)$ & $19(73)$ & $75(285)$ & $14(24)$ & $26(44)$ & $61(104)$ \\
\hline \multirow{2}{*}{$\begin{array}{l}\text { Take longer } \\
\text { breaks }\end{array}$} & no & $11(32)$ & $32(93)$ & 57(163) & $6(13)$ & $22(51)$ & 73(173) & $15(38)$ & $28(70)$ & $57(143)$ \\
\hline & yes & $7(11)$ & $32(52)$ & $62(102)$ & $6(13)$ & 19(46) & 75(179) & $13(14)$ & $23(25)$ & $64(70)$ \\
\hline \multirow{2}{*}{$\begin{array}{l}\text { Shorten the } \\
\text { workingday }\end{array}$} & no & $12(35)$ & $37(107)$ & $51(150)$ & $8(9)$ & $26(30)$ & $67(78)$ & $18(43)$ & $24(56)$ & $58(135)$ \\
\hline & yes & $4(7)$ & $25(40)$ & $71(114)$ & $5(18)$ & $19(68)$ & $76(277)$ & $7(9)$ & $30(39)$ & $63(81)$ \\
\hline \multirow{2}{*}{$\begin{array}{l}\text { Go home } \\
\text { and do } \\
\text { work later }\end{array}$} & no & $12(40)$ & $34(118)$ & $55(191)$ & $5(10)$ & $25(53)$ & 70(147) & $16(42)$ & $26(69)$ & $58(156)$ \\
\hline & yes & $3(3)$ & $28(30)$ & $69(73)$ & $6(17)$ & $18(47)$ & $76(204)$ & $11(11)$ & $27(26)$ & $62(61)$ \\
\hline \multicolumn{11}{|l|}{ Work } \\
\hline $\begin{array}{l}\text { disturb- } \\
\text { ance }\end{array}$ & yes & $7(9)$ & $25(34)$ & $69(94)$ & $6(10)$ & $16(28)$ & $78(135)$ & $18(23)$ & $23(30)$ & $59(75)$ \\
\hline Work from & no & $10(41)$ & $33(141)$ & $58(251)$ & $5(17)$ & $24(76)$ & $71(228)$ & $15(42)$ & $27(76)$ & 57(159) \\
\hline home & yes & $10(2)$ & $25(5)$ & $65(13)$ & $6(10)$ & $15(24)$ & $79(128)$ & $12(11)$ & 21(19) & $66(59)$ \\
\hline
\end{tabular}

When checking for potential confounders, having few opportunities to adjust compared to having many such opportunities increased men's likelihood to report both greatly $(\mathrm{OR}=3,6 \mathrm{Cl}=1,3 ; 10,6)$ 
and moderately reduced work ability $(\mathrm{OR}=1,8 \mathrm{Cl}=1,0 ; 3,1)$. Having an intermediate number of opportunities to adjust, compared to having many, increased the likelihood to report moderately reduced work ability among women $(\mathrm{OR}=1,8 \mathrm{Cl}=1,1 ; 3,0)$ and employees in health care $(\mathrm{OR}=2,3$ $\mathrm{Cl}=1,0 ; 5,3)$ (Table IV).

The opportunity to shorten the working day was associated with an increased likelihood to assess work ability as both greatly and moderately reduced among men and industrial employees when potential confounders were checked. For women and employees in health care, it was associated with greatly reduced ability. The opportunities to postpone work and choose among work tasks were associated with greatly reduced ability among men and industrial employees. To be able to go home and do work later and work without disturbance were associated with assessing work ability as both greatly and moderately reduced among men and employees in industry. To be able to work from home was, in the checked model, associated with moderately reduced work ability among women and employees in insurance (Table IV).

\section{Discussion}

This study shows that few opportunities to adjust work to health increased the likelihood among men to assess their work ability as reduced. For women, the association between adjustment latitude and self-assessed work ability was weaker. The number of opportunities to adjust was associated with self-assessed work ability only among employees in health care. The opportunity to shorten the working day when feeling ill was associated with self-assessed work ability in several of the groups studied. To go home and do work later, to be able to work without disturbance and to postpone work were among men and industrial employees associated with self-reported work 
Table IV Odds ratios (ORs) with 95\% confidence intervals for reporting greatly reduced and moderately reduced work ability in relation to adjustment latitude stratified by gender and occupational type

\begin{tabular}{|c|c|c|c|c|c|c|c|c|c|c|c|}
\hline & & \multicolumn{4}{|c|}{ Gender* } & \multicolumn{6}{|c|}{ Occupational type ${ }^{* *}$} \\
\hline & & \multicolumn{2}{|c|}{ Greatly reduced work ability } & \multicolumn{2}{|c|}{ Moderately reduced work ability } & \multicolumn{3}{|c|}{ Greatly reduced work ability } & \multicolumn{3}{|c|}{ Moderately reduced work ability } \\
\hline & & Women & Men & Women & Men & Industry & Insurance & Health care & Industry & Insurance & Health care \\
\hline & & $O R(C l 95 \%)$ & OR (CI 95\%) & $O R(C l 95 \%)$ & OR (Cl 95\%) & $O R(C I 95 \%)$ & OR (Cl 95\%) & $O R(C l 95 \%)$ & $O R(C I 95 \%)$ & $O R(C I 95 \%)$ & $O R(C l 95 \%)$ \\
\hline \multirow{3}{*}{$\begin{array}{l}\text { Adjustment } \\
\text { latitude } \\
\text { (Number of } \\
\text { opportunities) }\end{array}$} & few & $1,6(0,7 ; 3,5)$ & $3,6(1,3 ; 10,6)$ & $1,5(, 9 ; 2,5)$ & $\underline{1,8(1,0 ; 3,1)}$ & $2,4(, 7 ; 8,8)$ & $1,5(, 5 ; 4,8)$ & $2,0(, 7 ; 5,7)$ & $1,6(0,9 ; 3,0)$ & $1,5(, 8 ; 2,9)$ & $1,5(, 7 ; 3,3)$ \\
\hline & $\begin{array}{r}\text { inter- } \\
\text { mediate }\end{array}$ & $1,4(, 6 ; 3,5)$ & $1,2(, 4 ; 3,6)$ & $\underline{1,8(1,1 ; 3,0)}$ & $1,5(0,9 ; 3,1)$ & $0,8(0,2 ; 3,5)$ & $1,7(, 6 ; 4,9)$ & $1,5(, 4 ; 5,3)$ & $1,3(0,7 ; 2,6)$ & $1,6(0,9 ; 2,7)$ & $\underline{2,3(1,0 ; 5,3)}$ \\
\hline & many & 1 & 1 & 1 & 1 & 1 & 1 & 1 & 1 & 1 & 1 \\
\hline \multicolumn{12}{|c|}{ Specifik opportunities*** } \\
\hline Postpone work & No & $1,0(0,5 ; 1,9)$ & $\underline{4,3(1,9 ; 10)}$ & $1,2(, 8 ; 1,7)$ & $1,1(0,7 ; 1,7)$ & $2,9(1,2 ; 6,0)$ & , $7(0,2 ; 2,3)$ & $1,6(, 7 ; 3,4)$ & $1,2(0,8 ; 1,8)$ & $1,3(0,8 ; 2,3)$ & $1,0(, 6 ; 1,7)$ \\
\hline Choose among tasks & No & $1,3(0,7 ; 2,5)$ & $2,0(, 9 ; 4,5)$ & $1,1(0,8 ; 1,7)$ & $1,2(0,8: 1,8)$ & $1,4(, 6 ; 3,2)$ & $1,5(0,6 ; 4,2)$ & $1,7(, 8 ; 3,8)$ & $1,0(0,7 ; 1,6)$ & $1,1(0,7 ; 1,9)$ & $1,4(, 8 ; 2,3)$ \\
\hline $\begin{array}{l}\text { Get help from work } \\
\text { mates }\end{array}$ & No & $1,1(0,6 ; 2,1)$ & $1,4(0,6 ; 3,0)$ & $0,5(0,4 ; 0,8)$ & $0,9(0,6 ; 1,4)$ & $1,1(0,5 ; 2,7)$ & $1,6(0,7 ; 4,0)$ & $1,1(, 5 ; 2,2)$ & $0,7(0,4 ; 1,2)$ & $0,7(0,4 ; 1,1)$ &, $6(, 3 ;, 9)$ \\
\hline Work at a slower pace & No & $9(0,5 ; 1,7)$ & $1,2(0,6 ; 2,6)$ & $1,1(0,7 ; 1,6)$ & $9(0,6 ; 1,4)$ & $1,1(0,5 ; 2,4)$ & $0,7(0,2 ; 2,2)$ & $1,2(0,6 ; 2,4)$ &, $8(0,5 ; 1,3)$ & $1,3(0,8 ; 2,2)$ & $1,1(0,7 ; 1,8)$ \\
\hline Take longer breaks & No & $1,2(0,6 ; 2,4)$ & $1,5(0,7 ; 3,4)$ & $1,3(0,9 ; 1,8)$ & $1,1(0,7 ; 1,6)$ & $1,4(0,6 ; 3,4)$ & $1,3(0,5 ; 3,3)$ & $1,3(0,6 ; 3,0)$ & $1,1(0,7 ; 1,7)$ & $1,1(0,7 ; 1,8)$ & $1,4(0,8 ; 2,4)$ \\
\hline $\begin{array}{l}\text { Shorten the working } \\
\text { day }\end{array}$ & No & $\underline{2,2}(1,2 ; 4,3)$ & $\underline{2,9(1,2 ; 7,3)}$ & $1,3(, 9 ; 1,9)$ & $\underline{1,5}(1,0 ; 2,4)$ & $\underline{3,3(1,2 ; 8,7)}$ & $1,7(, 7 ; 4,6)$ & $\underline{2,6(1,1 ; 6,4)}$ & $\underline{2,0}(1,3 ; 3,2)$ & $1,5(, 9 ; 2,6)$ &, $8(, 5 ; 1,3)$ \\
\hline $\begin{array}{l}\text { Go home and do work } \\
\text { later }\end{array}$ & No & $1,1(0,6 ; 2,1)$ & $\underline{2,6(1,1 ; 6,6)}$ & $1,0(0,7 ; 1,5)$ & $\underline{2,1}(1,3 ; 3,3)$ & $\underline{4,4(1,2 ; 17)}$ & $0,9(0,4 ; 2,4)$ & $1,2(0,5 ; 2,8)$ & $1,4(0,8 ; 2,4)$ & $1,5(, 9 ; 2,4)$ & $1,0(0,6 ; 1,7)$ \\
\hline $\begin{array}{l}\text { Work without } \\
\text { disturbance }\end{array}$ & No & $0,7(0,4 ; 1,2)$ & $\underline{3,5(1,5 ; 8,0)}$ & $1,4(0,9 ; 2,1)$ & $\underline{1,9(1,2 ; 3,0)}$ & $\underline{3,6}(1,4 ; 9,4)$ & $1,0(0,4 ; 2,5)$ & , $7(0,3 ; 1,5)$ & $\underline{2,3(1,4 ; 3,8)}$ & $1,5(0,9 ; 2,5)$ & $1,1(0,7 ; 1,9)$ \\
\hline Work from home & No & $1,2(0,6 ; 2,6)$ & $1,9(0,6 ; 6,5)$ & $1,8(1,1 ; 3,0)$ & $1,5(, 8 ; 2,9)$ & $1,0(0,1 ; 9,9)$ & $1,1(0,4 ; 3,3)$ & $1,6(0,7 ; 3,7)$ & $1,3(, 4 ; 3,8)$ & $1,9(1,0 ; 3,1)$ & $1,5(0,8 ; 2,8)$ \\
\hline
\end{tabular}

*Controlled for age, SRH, work-place; ** controlled for age, $\mathrm{SRH}, * * *$ "yes" is reference 
ability. Among women and employees in insurance, the opportunity to work from home was associated with self-assessed work ability.

There are no previous studies of adjustment latitude and self-assessed work ability. The results from this study are, however, in accordance with a Norwegian study which showed that self- assessed work ability among patients visiting a GP was associated with working conditions [5]. These analyzes were, however, not stratified by gender or occupation. The weaker association between adjustment latitude and work ability among women is in line with Gamperiene and colleagues' [7] study of self-assessed work ability among female employees. This study did not reveal any associations between work ability and work environment conditions such as work stress and the extent to which the employee was able to make decisions about work.

The weaker associations between adjustment latitude and self-assessed work ability among women than men may reflect that higher proportions among women are working part time which may lessen the need for adjusting work when feeling ill. Especially an opportunity as shortening the working day may be less important for those already working shorter hours. Performing analysis on those working 35 hours or more a week did however not alter previous results.

Another possible explanation to this weaker association for women is they are more sensitive to health than men, which may explain why men, for example, are more involved in health risk behaviors and utilize health care less than women $[13,14]$. If women in general put more emphasis on health than men do, they may also put more emphasis on health than on working conditions when assessing work ability. 
The association between number and type of adjustment latitude and work ability differed between occupational sectors. Opportunities to adjust may have different meanings and significance in different work settings. For example, the opportunity "to go home and do work later", which was only associated with work ability among industrial employees, may have different implication in different occupational settings. In health care, it may mean that work mates have to carry a heavier burden and in insurance it may mean an accumulation of work tasks to be dealt with later. There is a need for studies focusing on the meaning and significance of using adjustment opportunities.

The opportunities to be able to "choose among tasks" "get help from work mates" "work at a slower pace" and "take longer breaks" were not associated with assessed work ability in any of the groups studied. We cannot generalize these results to assessed work ability when employees are in poor health, as all the study participants were in active employment. The importance of co-workers in enabling return to work for the long-term sick has been shown in a Swedish study [15]

Methodological considerations

Self-rated work ability was used in this study. Information on work ability can also be obtained by more "objective" methods such as external judgments by professionals. Most of the existing objectives methods can be regarded as assessments of function, that is, they assess an individual's capacity without taking working conditions into consideration [16]. It may, of course, be questioned whether self-reports reflect true work ability. However, subjective methods whereby individuals assess their own work ability correspond well with physicians' assessments for sick leave $[5,17,18]$. Self-assessed work ability also predicts sickness absence and early retirement.

The Work Ability Index (WAI) is the measure of work ability that is mostly used in research [19, 20]. However, we used a single-item-question measure of work ability as we agree with the criticism that WAI includes several disparate questions, some of which measure work ability indirectly, for 
example diagnosis of chronic conditions and sick leave [21]. This comprehensiveness of the WAI limits its usefulness for studies of, for instance, how work ability is related to health and sickness absence. However, the single item was found to have a strong correlation with WAI among women working in human service organizations who were currently on long-term sick leave [21].

Study population

As the sample in this study consisted of employees in active employment, we cannot generalize our results of assessments of work ability to include people who are off work due to sick leave. The importance of adjustment latitude for self-assessed work ability may differ for those on sick leave. A study by Reiso et al [5] on how patients recently sick-listed assess work ability revealed that stressful and physically strenuous work was associated with reduced ability. A previous study showed a strong association between adjustment latitude and return to work among the long-term sick, indicating that the association between adjustment latitude and self-assessed work ability may be even greater among those on sick leave [10].

Response rate

The low response-rate is a weakness in this study. Morton et.al state that although low participation itself does not necessarily compromise the internal validity of the study, information regarding participation is essential for readers to understand and to assess study results [22]. An important question is therefore if non-participants differed from participants in a way that affects the internal validity. Compared to non-participants, participants in this study had a lower annual sick leave incidence, were older and more often of female gender. There were no differences between work places in these aspects. This indicates that the differences reported between workplaces with regard to the association between adjustment latitude and work ability is not due to differences among responders. However, if adjustment latitude affects non-responders' assessments of work 
ability differently than responders' assessments, the associations found could be under- or overestimated. If, among non-responders, for example, it appeared that those with many opportunities to adjust are more likely to report reduced work ability than those with few opportunities, our results would be overestimated. If non-responders with few opportunities to adjust are more likely to report reduced work ability than responders, our results would be underestimated. However, we have no reason to believe that such differences exist between responders' and non-responders' assessments.

\section{Study design}

This study has a cross-sectional design, which is usually a problem in studies of causal relations, as the determinant is assumed to precede the outcome in time. However, according to the illness flexibility model, the latency between the determinant (e.g. adjustment latitude) and the outcome (work ability) is very short; in other words, individuals assess their work ability in relation to health and working conditions at the same moment of time. In tests of the illness flexibility model, it is therefore desirable that information about the potential determinants and work ability is collected simultaneously. The cross-sectional design is, however, a limitation, as it does not allow checking for previous adjustment latitude and work ability. Potential reversed causality between adjustment latitude and work ability can therefore not be excluded. If, for example, individuals with low work ability due to poor health tend to end up in jobs with high adjustment latitude, this may underestimate the association between adjustment latitude and work ability. If the opposite is true, that those with low work ability due to poor health are more likely to end up in jobs low in adjustment latitude, our results may overestimate this association.

A further possible drawback is that we have the same informants on predictors and outcomes. This will affect our results if the work ability influences the reporting of working conditions - if, for 
example, persons with poor health and low work ability are more likely to report lack of opportunities to adjust than persons with better health and work ability. Waldenström et al [23] found no systematic differences when comparing self-reports on working conditions with externally assessed working conditions among subjects with different levels of psychological distress. This indicates that use of the same informants does not have to be a problem. However, if such a reporting misclassification does exist, the effect of adjustment latitude on work ability will be exaggerated.

Implications

Adjustment latitude describes how flexible the working conditions are for an individual experiencing ill health and aims to capture working conditions that are irrespective of the individual. Another type of adjustment of work is any actual action taken to prevent sickness absence or to facilitate return to work for persons in poor health. In the literature, this is often called modified or accommodated work. It has been shown that modified work increases the likelihood to return to work and lowers the risk of recurrence of sick leave in comparison with returning directly to full duties after sick leave [24-26]. Furthermore, modified work has been found to be related to an early return to work $[27,28]$. Although adjustment latitude conceptually has to be kept apart from modified or accommodated work, most likely the results from this study can be applied when modifying work in vocational rehabilitation. Giving employees opportunities to shorten the working day when suffering health problems, for example, may improve work ability and enable those on long sick leave to return to work. Our findings also imply that opportunities to change working conditions to improve health should be considered in work ability assessments. This is in line with Nordenfelt [9], who suggests that opportunities to adjust are an important dimension in a work ability assessment. The extent to which work conditions are included in assessments of work ability has been shown to differ between different stakeholders. A recent Swedish study showed that 
Social Insurance officers related work ability to medical status, while health professionals had a more holistic view, relating work ability to a variety of factors [29].

According to the model of human occupations four main factors influence work behavior[30]. The first three, volition (senses, interests, values) habituation (maintaining regularity) and performance (innate capacities) are individual qualities. The fourth factor affecting work behavior is environment, Adjustment latitude may be such an environmental factor.

\section{Conclusion}

This study supports the assumption that adjustment latitude at work affects self-assessed work ability. If so, the impact differs in regard to gender and occupational sectors. As this is the first study of the relation between adjustment latitude and work ability, there is a need for studies with longitudinal design and alternative study populations.

\section{Acknowledgement}

\section{References}

1. Floderus B, Goransson S, Alexanderson K, Aronsson G. Self-estimated life situation in patients on long-term sick leave. J Rehabil Med 2005;37:291-299.

2. Bryngelson A. Long-term sickness absence and social exclusion. Scand J Public Health 2009;37:839845.

3. Sieurin $L$, Josephson $M$, Vingard E. Positive and negative consequences of sick leave for the individual, with special focus on part-time sick leave. Scand J Public Health 2009;37:50-56.

4. Johansson G. The illness flexibility model and sickness absence. Karolinska Institutet, Department of Public Health Sciences 2007.

5. Reiso H, Nygard JF, Brage S, Gulbrandsen P, Tellnes G. Work ability assessed by patients and their GPs in new episodes of sickness certification. Family practice 2000;17:139-144.

6. Martimo KP, Varonen H, Husman K, Viikari-Juntura E. Factors associated with self-assessed work ability. Occup Med (Lond) 2007;57:380-382.

7. Gamperiene M, Nygard JF, Sandanger I, Lau B, Bruusgaard D. Self-reported work ability of Norwegian women in relation to physical and mental health, and to the work environment. J Occup Med Toxicol 2008;3:8. 
8. Johansson G, Lundberg I. Adjustment latitude and attendance requirements as determinants of sickness absence and attendance. Empirical tests of the illness flexibility model. Soc Sci Med 2004;58:1857-1868.

9. Nordenfelt L. The Concept of Work Ability Peter Lang Pun Inc; 2008.

10. Johansson $\mathrm{G}$, Lundberg $\mathrm{O}$, Lundberg I. Return to work and adjustment latitude among employees on long-term sickness absence. J Occup Rehabil 2006;16:181-191.

11. Hultin $\mathrm{H}$, Hallqvist J, Alexanderson K, Johansson $\mathrm{G}$, Lindholm C, Lundberg I, et.al. Low level of adjustment latitude--a risk factor for sickness absence. Eur J Public Health 2010;20:682-688.

12. Johansson $\mathrm{G}$, Lundberg I. Components of the illness flexibility model as explanations of socioeconomic differences in sickness absence. Int J Health Serv 2009;39:123-138.

13. Kandrack MA, Grant KR, Segall A. Gender differences in health related behaviour: some unanswered questions. Soc Sci Med 1991;32:579-590.

14. Koopmans GT, Lamers LM. Gender and health care utilization: the role of mental distress and helpseeking propensity. Soc Sci Med 2007;64:1216-1230.

15. Tjulin A, Maceachen E, Ekberg K. Exploring Workplace Actors Experiences of the Social Organization of Return-to-Work. J Occup Rehabil 2010;20:311-321.

16. McFadden S, MacDonald A, Fogarty A, Le S, Merritt BK. Vocational assessment: a review of the literature from an occupation-based perspective. Scand J Occup Ther 2009;17:43-48.

17. Reiso H, Nygard JF, Brage S, Gulbrandsen P, Tellnes $G$. Work ability and duration of certified sickness absence. Scand J Public Health 2001;29:218-225.

18. Lotters F, Burdorf A. Prognostic factors for duration of sickness absence due to musculoskeletal disorders. Clin J Pain 2006;22:212-221.

19. Ilmarinen J. The Work Ability Index (WAI). Occup Med (Lond) 2007;57:160-160.

20. Ilmarinen J. Work ability--a comprehensive concept for occupational health research and prevention. Scand J Work Environ Health 2009;35:1-5.

21. Ahlstrom L, Grimby-Ekman A, Hagberg M, Dellve L. The work ability index and single-item question: associations with sick leave, symptoms, and health--a prospective study of women on long-term sick leave. Scand J Work Environ Health; 36:404-412.

22. Morton L, Cahill J, Hartge P. Reporting participation in epidemioloic studies: a survey of practice. Am J Epidemiol 2005;163:197-203.

23. Waldenström K, Lundberg I, Waldenström M, Härenstam A, MOA Research Group. Does psychological distress influence reporting of demands and control at work. Occup Environ Med 2003; 60:887-891.

24. Van Duijn M, Burdorf A. Influence of modified work on recurrence of sick leave due to musculoskeletal complaints. J Rehabil Med 2008;40:576-581.

25. Krause N, Dasinger L, Neuhauser F. Modified work and return to work: A review of the literature. J Occup Rehabil 1998;8:113-139.

26. Weir R, Nielson WR. Interventions for disability management. Clin J Pain 2001;17:128-132.

27. Franche RN, Cullen K, Clarke J, Irvin E, Sinclair S, Frank J. Workplace-based return-to-work interventions: A systematic review of the quantitative literature. J Occup Rehabil 2005;15:607-631.

28. Franche RN, Severin C, Hogg-Johnson S, Cote P, Vidmar M, Lee H. The impact of early workplace-based return-to-work strategies on work absence duration: A 6-month longitudinal study following an occupational musculoskeletal injury. J Occup Environ Med 2007;49:960-974.

29. Stahl C, Svensson T, Petersson G, Ekberg K. The work ability divide: holistic and reductionistic approaches in Swedish interdisciplinary rehabilitation teams. J Occup Rehabil 2009;19:264-273.

30. Kielhofner G, Braveman B, Baron K, Fisher G, Hammel J, Littleton M. The model of human occupation:understanding the worker who is injued or disabled. Work 1999;12:37-45. 